\title{
Breast Cancer in Adolescents and Young Adults: A Review With a Focus on Biology
}

\author{
Jill R. Tichy, MDa; Elgene Lim, MD, PhD ${ }^{\mathrm{b}}$; and Carey K. Anders, MDa
}

\begin{abstract}
Breast cancer is a substantial contributor to adolescent and young adult (AYA) malignancies, defined as a diagnosis of cancer between the ages of 15 and 39. In the United States, $6.6 \%$ of breast cancer cases are diagnosed among women younger than 40 years. When breast cancer occurs in AYAs, it typically has a worse prognosis and more-aggressive phenotype; higher proportions of high-grade and later-stage tumors; lower estrogen receptor positivity; and, in some studies, higher expression of HER2. Age-specific differences in the biology of AYA breast cancer have been explored in large-scale genomic studies with mixed results. Although some studies suggest that AYA breast cancer has a unique biology, others have shown that its aggressive nature is the result of higher frequencies of aggressive breast cancer subtypes among younger patients. More recently, stromal-related gene signatures have shown prognostic significance in AYA breast cancer, suggesting that differences in microenvironment may account for age-specific differences in breast cancer behavior. Although general principles for selecting cytotoxic and targeted agents are similar between AYAs and the general breast cancer population, endocrine therapy choices in the adjuvant and metastatic settings vary by preand postmenopausal status. The role of ovarian suppression remains controversial and is reviewed. The AYA population is a unique group of patients who need individualized care, including considerations of hereditary breast cancer predispositions, future fertility, and the effect of therapy on immediate and long-term quality of life, all of which require coordinated
\end{abstract}

From the aUniversity of North Carolina at Chapel Hill, Lineberger Comprehensive Cancer Center, Chapel Hill, North Carolina, and

'Dana-Farber Cancer Institute, Boston, Massachusetts.

Submitted January 10, 2013; accepted for publication May 9, 2013.

The authors have disclosed that they have no financial interests, arrangements, affiliations, or commercial interests with the manufacturers of any products discussed in this article or their competitors. The project described was supported by Grant Number K23CA157728 (CKA) from the National Cancer Institute. The content is solely the responsibility of the authors and does not necessarily represent the official views of the National Cancer Institute or the National Institutes of Health. Dr. Anders is a Damon Runyon Clinical Investigator supported (in part) by the Damon

Runyon Cancer Research Foundation (Cl-64-12).

Correspondence: Carey K. Anders, MD, University of North Carolina at Chapel Hill, 170 Manning Drive, CB 7305, Chapel Hill, NC 27599-

7305. E-mail: carey_anders@med.unc.edu multidisciplinary care. This article addresses the epidemiology, genetics, and management of breast cancer in AYA women and highlights unique medical issues important to this population. (JNCCN 2013;11:1060-1069)

Adolescents and young adults (AYAs) are defined as individuals aged 15 to 39 years, and represent approximately 70,000 new cancer cases diagnosed annually. ${ }^{1}$ Compared with other age groups, AYAs have experienced little improvement in cancer-related survival over the past 2 decades. ${ }^{2}$ Several factors may explain the poor outcomes observed in this population, which may include a limited understanding of the biology of these cancers, inadequate clinical trial representation, and unique psychosocial and supportive care needs. In 2005-2006, a progress review group issued "Closing the Gap: Research and Care Imperatives for AYAs With Cancer" with the intent to solicit recommendations for a national agenda to focus efforts on this demographic. ${ }^{2}$ Years later, efforts to provide more comprehensive care to this distinct population continue.

Evidence suggests that breast cancer in AYAs may be clinically and etiologically distinct from breast cancer in older women. When breast cancer occurs in AYAs, it has a worse prognosis and more-aggressive phenotype, higher proportions of high-grade and later-stage tumors, lower estrogen receptor (ER) positivity, and, in some studies, higher expression of HER2. ${ }^{3-5}$ Furthermore, a young woman with invasive breast cancer is at higher risk for developing a second breast cancer. Understanding the challenges of AYA breast cancer requires an appreciation of numerous complex issues, which highlight treatment challenges and longterm physical and psychosocial effects. Germline mutations in genes known to predispose to breast cancer play a role in a relative minority of patients, yet lend additional challenges to the treatment approach to this disease. 


\section{Epidemiology}

Breast cancer is the most frequently diagnosed cancer among AYA women between 25 and 39 years of age, accounting for approximately $14 \%$ of all AYA cancer diagnoses. ${ }^{2,3}$ The risk of breast cancer increases with age; however, postmenopausal women have experienced a significant downward trend in breast cancer incidence, partly because of a lower use of hormone replacement therapy. ${ }^{6}$ In contrast, breast cancer incidence in women younger than 45 years remains stable. ${ }^{7}$ In the United States, approximately 200,000 breast cancer cases are reported per year, of which $6.6 \%(\approx 13,000)$ are diagnosed among women younger than 40 years $^{7}$ (Figure 1). Although some reports project that the AYA proportions of annual new cancer cases and cancer deaths will decline relative to other age groups, the overall cancer burden is anticipated to increase because of the projected growth of the US population. ${ }^{8}$

Globally, breast cancer is the most frequently diagnosed cancer in women regardless of age. Incidence and mortality rates seem to be increasing in less-developed countries compared with the United States and other westernized countries. ${ }^{9,10}$ Poor use of screening efforts and the adoption of a western lifestyle in many of the economically transitioning countries are presumed to be the driving force for this increase. Many developing countries experiencing increasing rates of breast cancer, including Asian and Latin American countries, show a younger age at peak incidence compared with Western countries. ${ }^{11}$ AYA breast cancer is still considerably rare globally, and the cumulative risk of "very young" breast cancer development ( $<40$ years of age) is estimated to be less than $1 \%$ in all countries. ${ }^{10}$

\section{Biology of AYA Breast Cancer}

The biology of breast cancer arising in a younger, compared with older, host has long been a topic of research, and more recently debate. Historically and before the advent of large-scale genomic studies, descriptive studies consistently illustrated that breast cancer arising in young women harbors a more aggressive phenotype than that in older women. ${ }^{12-16}$ More recently, an analysis of SEER data from 1976 through 2009 identified an increase in the incidence of metastatic breast cancer among those aged 25 to 39 years at diagnosis, without a corresponding increase among older women. ${ }^{17}$ Collectively, studies have identified higher rates of hormone receptor negativity, higher-grade breast tumors, and higher rates of lymphovascular invasion in AYA women compared with older counterparts. ${ }^{14-16}$ In contrast,

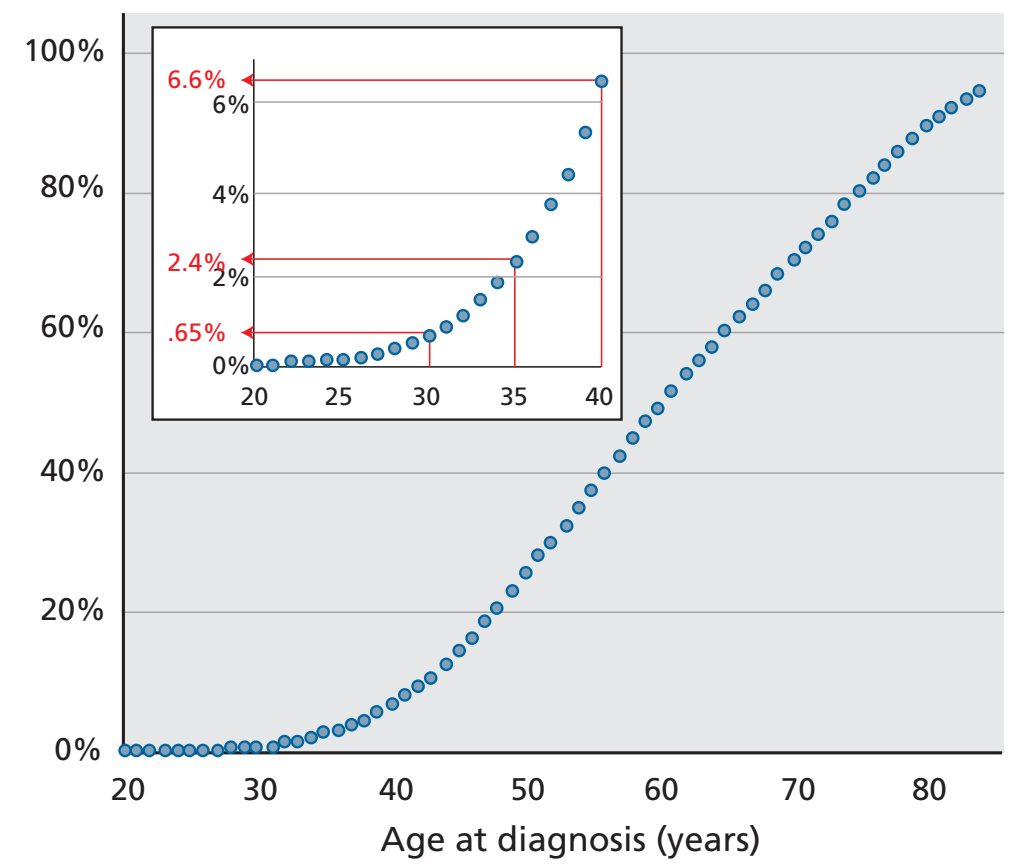

Figure 1 Cumulative percent of breast cancer in women from SEER17 between 2000 and 2005.

From Anders CK, Johnson R, Litton J, et al. Breast cancer before age 40 years. Semin Oncol 2009;36:237-249; with permission. 
Tichy et al

age-specific differences in tumor size, lymph node positivity, and rates of HER2 overexpression have been less clear. ${ }^{18,19}$

To further explore age-specific differences in breast cancer biology, several groups have evaluated differential gene expression in breast tumors from younger versus older women. Anders et $\mathrm{al}^{19}$ evaluated clinically annotated gene expression data on more than 700 breast tumors from 4 data sets in an age-specific manner ( $\leq 45$ vs $\geq 65$ years) to better understand the biology underlying breast cancer arising in a younger host. Consistent with prior reports, younger women were less likely to be diagnosed with $\mathrm{ER}^{+}$tumors as defined by immunohistochemistry ( $71 \%$ vs $80 \% ; P=.27$ ), yet more likely to be diagnosed with grade III ( $56 \%$ vs $26 \%$; $P<.0001$ ), nodepositive ( $38 \%$ vs $25 \% ; P=.008$ ), and larger breast tumors (defined as $>$ T2 ; $62 \%$ vs $47 \%$; $P=.012$ ). Interestingly, mRNA expression for $E R \alpha, E R \beta$, and $P R$ was significantly lower, whereas mRNA expression of HER2 and epidermal growth factor receptor (EGFR; HER1) was significantly higher in breast tumors from women aged 45 years or younger compared with those aged 65 years or older. When evaluating gene sets unique to breast tumors arising from younger women compared with older women using Gene Set Enrichment Analysis, 367 sets significantly distinguished breast tumors in younger women. Many of these gene sets were of biologic importance, playing roles in immune function, hypoxia, stem cell biology, apoptosis, p53 and BRCA1 function, and targetable pathways such as mTOR/rapamycin and PTEN (indirectly through the PI3K pathway).

More recently, Azim et al ${ }^{20}$ conducted a similar analysis to further elucidate the biology and prognosis of breast cancer arising in younger women using 20 clinically annotated gene expression databases including more than 3500 treated and treatmentnaïve patients. In this comprehensive analysis, breast cancer subtype was defined using a 3-gene classifier: ESR1, ERBB2 [HER2], and AURKA. The prognostic value of 3 proliferation-related, 3 stromal-related, and 3 immune-related gene signatures were evaluated by age. Interestingly, although proliferation and immune-related gene signatures did not add prognostic information in an age-specific manner, stromal-related gene signatures showed a significant interaction with age in aggressive $\mathrm{ER}^{-} / \mathrm{HER}^{-}$breast cancers (hazard ratio [HR], 2.4; $P=.04$; for patients aged $\leq 40$ years). In addition and using a candidate gene approach, 41 genes and 13 gene sets were evaluated in an age-specific manner and then corrected for 3-gene classifier breast cancer subtype, tumor size, nodal status, and grade. Twelve gene sets were significantly age-dependent in 2 independent data sets and were related to immature mammary cell populations (eg, RANKL, c-kit, BRCA1-mutated phenotype, mammary stem cells, luminal progenitors cells) and growth factor signaling (MAPK, PI3K-related).

The medical community is becoming increasingly aware of the fact that breast cancer is no longer viewed as a single disease process, but rather as multiple different subsets of disease with unique molecular and phenotypic differences. ${ }^{21-23}$ Thus, several investigators have questioned whether the biology of breast cancer arising in younger women is truly unique from that of older women or is perhaps a surrogate for more aggressive subtypes, including the basal-like and HER2-enriched subtype. To help address this query, Anders et $\mathrm{a}^{24}$ evaluated age-specific differences in breast cancer biology, taking a subtype-specific approach (as defined by the PAM50 [Predictor Analysis of Microarray]). ${ }^{24,25}$ Results of this analysis illustrated, in 2 independent data sets of approximately 200 samples each, that the basallike and HER2-enriched breast cancer subtypes were overrepresented among women aged 45 years and younger, whereas luminal A and B breast cancers were overrepresented among those aged 65 years and older. Moreover, when evaluating age-specific gene expression differences by age alone, 693 and 2154 genes were differentially expressed by age in independent data sets $\mathrm{A}$ and $\mathrm{B}$, respectively. When corrected for PAM50 subtype and other significantly different factors (eg, grade, ER status, data set source), gene expression differences diminished to 0 and 1 , respectively.

Collectively, the studies outlined earlier have led many to hypothesize that differences observed between breast cancers arising in younger versus older women may be related less to intratumoral biologic differences than to the vast differences in the microenvironment of a premenopausal versus postmenopausal host. Moreover, the cause for the overrepresentation of more aggressive subtypes arising in younger women is not completely understood. One potential hypothesis relates to the composition of the younger, premenopausal breast compared with 
breast tissue in an older, postmenopausal host. Four subpopulations of human mammary cells with distinct gene signatures were previously characterized: stromal $\left(\mathrm{CD}^{2} 9 \mathrm{f}^{-} \mathrm{EpCAM}^{-}\right)$, mature luminal (CD49f$\left.\mathrm{EpCAM}^{+}\right)$, luminal progenitor $\left(\mathrm{CD} 49 \mathrm{f}^{+} \mathrm{EpCAM}^{+}\right)$, and mammary stem cell (MaSC)-enriched

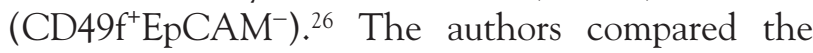
relative proportions of mammary epithelial cells in reduction mastectomy tissue obtained from women younger $(n=35)$ and older than 50 years $(n=12)$, using data obtained from standardized tissue digest conditions (Figure 2A). ${ }^{26}$ The stromal subset varied significantly between women in both age groups and was therefore excluded from the analysis. A statistically significant difference was found in the relative proportion of the 3 epithelial cell subsets when expressed as a percentage of the total number of epithelial cells, with an expansion of the luminal progenitors $(P=.016)$ and mature luminal epithelial cells $(P=.168)$ and a corresponding decrease in the MaSC-enriched subset $(P=.001)$ in the older subgroup (Figure $2 \mathrm{~B}$ ). This finding is most likely related to the decrease in serum estradiol and progesterone levels with menopause. Gene expression profiling of these subpopulations revealed similarities to specific subtypes of breast cancer, and most breast cancer subtypes were more similar to the luminal progenitor and mature luminal subpopulations. ${ }^{26}$ Because age is an established breast cancer risk factor, these findings suggest that the expanded luminal subpopulations may be a potential target of tumorigenesis in older women.

\section{Special Issue of Relevance to AYAs: Hereditary Breast Cancer}

Accounting for fewer than $10 \%$ of all breast cancer diagnoses, the genes most commonly implicated in familial breast cancers are BRCA, p53, and PTEN. Several other genes are involved in rare syndromes, and many others have yet to be determined. The 2 most prevalent breast cancer susceptibility genes, BRCA1 and BRCA2, account for $66 \%$ to $75 \%$ of hereditary breast cancer in the United States and Western Europe, and confer a 10-fold increase in the relative risk of breast cancer. ${ }^{27}$ The average age of a breast cancer diagnosis among women with the BRCA1 mutation is 42 years, which is 20 years earlier than population averages. ${ }^{28}$ In a population-based case-control study, when focusing primarily on age and no other risk factors such as family history or Ashkenazi ancestry, the probability a woman younger than 35 years harboring a BRCA1/2 mutation was $9.4 \%$ compared with a population control of $0.2 \% .{ }^{29}$ Specific tumor characteristics are also associated with BRCA mutation status. BRCA1 breast cancers are more frequently associated with higher grade, hormone receptor negativity, and the basal-like subtype. $^{30}$ One study reports the incidence of BRCA1 mutations to be $15.6 \%$ among 77 women with triplenegative breast cancer across all age groups (range, $27-83$ years). ${ }^{31}$ BRCA2 is more commonly associated with hormone receptor-positive and luminal subtypes; histologically these tumors are not very different from sporadic breast cancers. ${ }^{32}$ The lifetime risk of contralateral breast cancer in BRCA1 and BRCA2 carriers is estimated to be between $50 \%$ and $64 \% .^{33}$

Other less common genetic abnormalities accounting for fewer than $1 \%$ of breast cancer cases include Li-Fraumeni syndrome (LFS) and Cowden disease, which is also known as multiple hamartoma syndrome. LFS, caused by mutation in the $p 53$ gene, is characterized by early-onset breast cancers, among other malignancies, such as brain tumors, leukemia, sarcomas, and adrenocortical adenomas. Breast cancer is the most frequent tumor in LFS, ${ }^{34}$ and of those with germline TP53 mutations, nearly one-third develop breast cancer before 30 years of age. Recent reports identify an increased frequency of HER2-amplified breast cancer in women with LFS. ${ }^{35-37}$ Although somatic mutations in the TP53 gene are frequent in sporadic basal (83\%) and HER2-amplified (70\%) breast cancer subgroups, ${ }^{38}$ the reason for an apparent increase in HER2-amplified breast cancer in LFS is unclear, and may potentially relate to the effect of germline TP53 loss on different cells of origin or as the initial oncogenic event. Cowden disease, caused by mutations in the PTEN gene, is exceedingly rare and is also associated with other tumors, particularly of the skin, thyroid, and endometrium. ${ }^{39}$

Genetic counseling plays a paramount role in decision-making for young women diagnosed with breast cancer and has significant implications for family members. A breast cancer diagnosis of any hormone receptor or HER2/neu status in women aged 50 years and younger warrants a referral to a genetic counselor. ${ }^{40}$ In addition, the NCCN Clinical Practice Guidelines in Oncology (NCCN Guide- 
Tichy et al

A

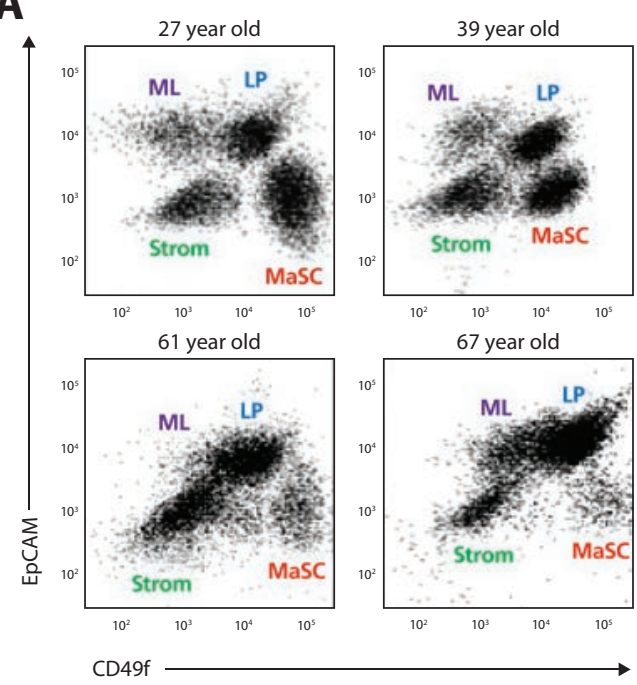

B

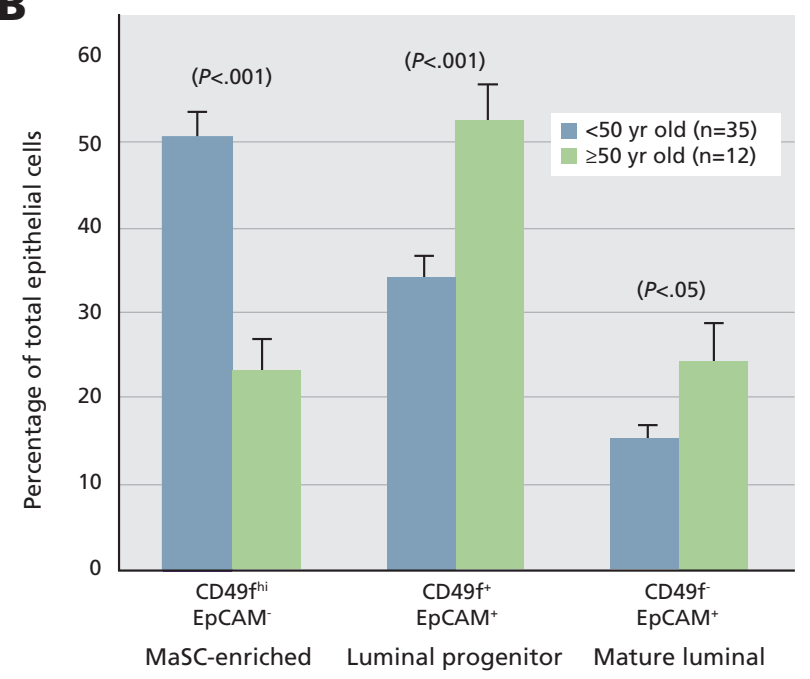

Figure 2 Comparison of the relative proportion of human mammary epithelial cell subpopulations from reduction mastectomies in women younger than 50 years and those aged 50 years and older. (A) Representative fluorescence-activated cell sorter dotplots showing the expression of CD49f and EPCAM from women younger than 50 years and those aged 50 years and older. (B) Bar chart depicting the relative proportion of epithelial cell subpopulations in normal breast tissue from women younger than 50 years (blue bars; $n=35$ ) and those aged 50 years and older (green bars; $n=12$ ). Mammary stem cell-enriched (MaSC; CD49fhiEpCAM-), luminal progenitor (LP; CD49f+EpCAM+), and mature luminal (ML; CD49f-EpCAM+) subpopulations are expressed as a percentage of the total number of epithelial cells in the 3 subpopulations. Data represent mean \pm standard error of the mean.

Abbreviation: Strom, stromal cells.

lines) for Genetic/Familial High-Risk Assessment: Breast and Ovarian include specific recommendations for women diagnosed with triple-negative breast cancer. ${ }^{40}$ According to the most recent version of these guidelines (available at NCCN.org), a diagnosis of triple-negative breast cancer at any age warrants genetic risk evaluation given the high incidence of germline mutations in this patient population. ${ }^{40}$ Diagnosis of a familial breast cancer syndrome has implications for risk of secondary malignancy increased by radiation treatment, in particular in those with LFS and additional treatment decisions including consideration of prophylactic surgeries (ie, prophylactic mastectomy and/or prophylactic bilateral salpingo-oophorectomy) that have been shown to improve outcomes for this patient population. ${ }^{41,42}$

\section{Therapeutic Considerations}

As younger women with breast cancer commonly present with more aggressive disease, balancing the benefits of (neo)adjuvant therapy with long-term sequelae of treatment is paramount. Moreover, some iniquities are specific to the care of young women diagnosed with breast cancer, and therefore all AYA patients diagnosed with breast cancer should be informed of the possibility of clinical trial participation at diagnosis and throughout their treatment course. This section addresses endocrine therapy in adjuvant and metastatic settings, the controversy of ovarian suppression, and strategies with cytotoxic chemotherapy/targeted agents.

\section{Endocrine Therapy: Adjuvant Setting}

Adjuvant tamoxifen in premenopausal women remains the standard of care for women with hormone receptor-positive breast cancer. ${ }^{43}$ The relative benefit of ovarian suppression or ablation in conjunction with tamoxifen remains controversial. Results are awaited of SOFT (Intergroup Suppression of Ovarian Function), a prospective randomized study of tamoxifen alone versus tamoxifen plus ovarian suppression in premenopausal women with early-stage breast cancer. Until these data are available, the results of several studies addressing this question must provide guidance (Table 1).

In the Early Breast Cancer Trialist's Collaborative Group (EBCTCG) review, ovarian ablation was associated with a significantly decreased risk of recurrence and mortality when compared with placebo. ${ }^{44}$ In addition to evaluating the effects of adding zoledronic acid to adjuvant endocrine therapy, the Austrian Breast Cancer Study Group (ABCSG) XII compared tamoxifen plus goserelin versus anas- 
Breast Cancer in Young Women

\begin{tabular}{|c|c|c|c|}
\hline Trials & $\mathbf{N}$ & Treatment Group & Outcome \\
\hline \multirow{2}{*}{$\begin{array}{l}\text { Early Breast Cancer } \\
\text { Trialists' Collaborative } \\
\text { Group, }^{44} 1996\end{array}$} & \multirow[t]{2}{*}{2102} & \multirow{2}{*}{$\begin{array}{l}\text { Ovarian ablation/suppression } \\
\text { or } \\
\text { Control }\end{array}$} & $\begin{array}{l}\text { OS: } 52 \% \text { for ovarian ablation vs } 46 \% \\
(2 P=.001)\end{array}$ \\
\hline & & & $\begin{array}{l}\text { RFS: } 45 \% \text { for ovarian ablation vs } 39 \% \\
(2 P=.0007)\end{array}$ \\
\hline \multirow[t]{4}{*}{ Gnant et al, ${ }^{45} 2009$} & \multirow[t]{4}{*}{1803} & \multirow{2}{*}{$\begin{array}{l}\text { Goserelin + tamoxifen } \\
\text { or } \\
\text { Goserelin + anastrozole }\end{array}$} & Median follow-up: 47.8 months \\
\hline & & & $\begin{array}{l}\text { OS: HR for anastrozole } 1.80(95 \% \mathrm{Cl} \text {, } \\
0.95-3.38 ; P=.07)\end{array}$ \\
\hline & & \multirow[t]{2}{*}{$\begin{array}{l}+/- \text { zoledronic acid in a } \\
1: 1: 1: 1 \text { study design }\end{array}$} & $\begin{array}{l}\text { DFS: NS difference (tamoxifen } 92.8 \% \\
\text { and anastrozole } 92.0 \% \text { ) }\end{array}$ \\
\hline & & & $\begin{array}{l}\text { HR for DFS in anastrozole: } 1.10(95 \% \\
\mathrm{Cl}, 0.78-1.53 ; P=.59)\end{array}$ \\
\hline \multirow[t]{3}{*}{ Roche et al, ${ }^{46} 2006$} & \multirow[t]{3}{*}{333} & LHRH agonist + tamoxifen & \multirow{2}{*}{$\begin{array}{l}\text { OS at } 7 \text { years: NS difference between } \\
\text { LHRH agonist }+ \text { tamoxifen vs FEC50 } \\
(91 \% \text { vs } 88 \% \text {, respectively; } P=.20)\end{array}$} \\
\hline & & \multirow{2}{*}{$\begin{array}{l}\text { Fluorouracil, epirubicin, } \\
\text { cyclophosphamide x } 6 \text { cycles } \\
\text { without hormonal treatment }\end{array}$} & \\
\hline & & & $\begin{array}{l}\text { DFS at } 7 \text { years: NS difference between } \\
\text { LHRH agonist + tamoxifen vs FEC50 } \\
(76 \% \text { vs } 72 \% \text {, respectively; } P=.13)\end{array}$ \\
\hline \multirow[t]{2}{*}{ Klijn et al, ${ }^{47} 2001$} & \multirow[t]{2}{*}{506} & \multirow[t]{2}{*}{$\begin{array}{l}\text { LHRH agonist alone } \\
\text { or } \\
\text { LHRH agonist + tamoxifen }\end{array}$} & $\begin{array}{l}\text { OS: treatment effect for } \mathrm{LHRH}+ \\
\text { tamoxifen }(\mathrm{HR}, 0.78 ; 95 \% \mathrm{Cl}, 0.63- \\
0.96)\end{array}$ \\
\hline & & & $\begin{array}{l}\text { PFS: treatment effect for } \mathrm{LHRH}+ \\
\text { tamoxifen (HR, } 0.70 ; 95 \% \mathrm{Cl}, 0.58- \\
0.85)\end{array}$ \\
\hline \multirow[t]{5}{*}{ Cuzick et al, ${ }^{48} 2007$} & 11,906 & \multirow{2}{*}{$\begin{array}{l}\text { A) LHRH agonist alone } \\
\text { or } \\
\text { no systemic treatment }\end{array}$} & \multirow{2}{*}{$\begin{array}{l}\text { A) Recurrence: no treatment effect for } \\
\text { LHRH agonist alone (HR, 0.72; } 95 \% \mathrm{Cl} \text {, } \\
0.49-1.04 ; P=.08)\end{array}$} \\
\hline & \multirow{4}{*}{$\begin{array}{l}\text { (9022 were } \\
\text { hormone receptor- } \\
\text { positive) }\end{array}$} & & \\
\hline & & \multirow{3}{*}{$\begin{array}{l}\text { B) LHRH agonist + tamoxifen } \\
\text { vs tamoxifen } \\
\text { or } \\
\text { LHRH agonist }+ \\
\text { chemotherapy ( } \pm \text { tamoxifen) }\end{array}$} & $\begin{array}{l}\text { Death after recurrence (HR, } 0.82 ; 95 \% \\
\mathrm{Cl}, 0.47-1.43 ; P=.49)\end{array}$ \\
\hline & & & $\begin{array}{l}\text { B) Recurrence: } \mathrm{LHRH} \text { agonist }+ \\
\text { tamoxifen with no significant effect } \\
\text { on recurrence (HR, } 0.85 ; 95 \% \mathrm{Cl}, 0.67- \\
1.09 ; P=.2) \text { or death after recurrence } \\
(\mathrm{HR}, 0.84 ; 95 \% \mathrm{Cl}, 0.59-1.19 ; P=.33)\end{array}$ \\
\hline & & & $\begin{array}{l}\text { Recurrence: addition of LHRH agonist } \\
\text { reduces recurrence }(\mathrm{HR}, 0.88 ; 95 \% \\
\mathrm{Cl}, 0.77-0.99 ; P=.04) \text { and death } \\
\text { after recurrence }(\mathrm{HR}, 0.85 ; 95 \% \mathrm{Cl}, \\
0.73-0.99 ; P=.04) \text {. }\end{array}$ \\
\hline
\end{tabular}

Abbreviations: DFS, disease-free survival; HR, hazard ratio; LHRH, luteinizing hormone-releasing hormone; FEC50, fluorouracil, epirubicin, cyclophosphamide; NS, nonsignificant; OS, overall survival; PFS, progression-free survival; RFS, relapse-free survival.

trozole plus goserelin in early-stage, premenopausal, hormone receptor-positive breast cancer. In this analysis, no significant difference was seen in the primary end point of disease-free survival between the treatment groups. ${ }^{45}$ The ABCSG 5 study showed that tamoxifen plus ovarian suppression resulted in similar 7 -year disease-free and overall survivals as adjuvant cytotoxic chemotherapy with 5-fluorouracil/epirubicin/cyclophosphamide (FEC). As expected and from a quality-of-life ( $\mathrm{QoL}$ ) perspective, tamoxifen plus ovarian suppression was better tolerated than FEC in this analysis. ${ }^{46} \mathrm{Klijn}$ et $\mathrm{al}^{47}$ reported on a meta-analysis of premenopausal, chemotherapy-naïve women who received luteinizing hormone-releasing hormone (LHRH) agonist alone with or without tamoxifen. Results of the meta-analysis suggest a significant difference in survival in favor of combined treatment (HR, 0.78; 95\% CI, 0.63, 0.96). Finally, a metaanalyses of approximately 11,906 premenopausal women with early-stage breast cancer from 16 trials illustrated that, although LHRH as a sole therapy did not improve outcome, the addition of an LHRH agonist to tamoxifen, chemotherapy, or both reduced recurrence $(12.7 \% ; P=.02)$ and death after recurrence (15.1\%; $P=.03) .{ }^{48}$ Based on these data collectively, 
Tichy et al

current NCCN Guidelines for Breast Cancer recommend that adjuvant endocrine therapy for premenopausal women consist of 5 years of tamoxifen (category 1 ) with or without ovarian ablation (category $2 \mathrm{~b}$ ), as guided by the patient's individual risk for breast cancer recurrence and preference (to view the most recent version of these guidelines, visit NCCN.org. ${ }^{43}$ The most recent version of the NCCN Guidelines have an option of extending tamoxifen therapy for an additional 10 years based on the ATLAS trial data (BINV-J; available online, in the NCCN Guidelines for Breast Cancer, at NCCN.org).

\section{Endocrine Therapy: Metastatic Setting}

In the absence of visceral crises warranting up-front systemic chemotherapy, tamoxifen remains the preferred first line of therapy for premenopausal women with hormone receptor-positive metastatic breast cancer. NCCN Guidelines recommend treatment with ovarian suppression or ablation, in addition to endocrine therapy, in the metastatic setting. ${ }^{43}$ Once deemed physiologically postmenopausal or in the presence of biochemical menopause, treatment with an aromatase inhibitor and/or fulvestrant may be indicated. Notably, a small phase II study of anastrozole and goserelin to treat premenopausal women with hormone receptor-positive, metastatic breast cancer showed response rates of $37.5 \%$ and clinical benefit rates of approximately $70 \%$. Results are similar to those for the postmenopausal patient population. ${ }^{49}$

\section{Cytotoxic Chemotherapy and Biologic Therapies}

In contrast to that of endocrine therapy, the major principles guiding the use of cytotoxic chemotherapy and/or targeted agents, including HER2-directed therapy, remain relatively similar between pre- and postmenopausal patients with breast cancer. In the (neo)adjuvant setting, the TNM (tumor/nodal/metastases) staging system serves to guide the decision to initiate cytotoxic chemotherapy. Interestingly, a recent report of 8949 patients from 8 neoadjuvant German studies with inoperable or locally advanced, nonmetastatic breast cancer, of which 704 patients were younger than 35 years, compared the pathologic complete response ( $\mathrm{pCR}$ ) rates and subtype distribution of patients younger than 35 years and aged 35 years and older. ${ }^{50}$ Although the $\mathrm{pCR}$ rate was higher in patients younger than 35 years $(23.6 \%$ vs $15.7 \%$, respectively; $P<.0001$ ), this effect was driven mainly by the hormone receptor-positive/HER2 ${ }^{-}(P=.13)$ and triple-negative breast cancer subsets $(P=.004)$. Moreover, when selecting cytotoxic chemotherapy for young women, the impact of side effects on longterm health must be considered (eg, cardiac reserve, secondary malignancies such as leukemia, future fertility). Timing of chemotherapy as it relates to future fertility is of paramount importance, whether it relates to oocyte, ovarian tissue, or embryo cryopreservation, and/or the use of gonadotropin-releasing hormone $(\mathrm{GnRH})$ analogs or antagonists during chemotherapy. All women of childbearing potential diagnosed with breast cancer should be educated about the risk of infertility at the earliest opportunity, offered fertility preservation, and referred to a reproductive specialist as appropriate..$^{51}$ Finally, the decision to recommend chemotherapy, in addition to standard local and endocrine therapies, should be individualized, because the incremental benefit may be small in patients with favorable-prognosis tumors.

\section{QoL, Relationships, and Family Planning}

Young women diagnosed with breast cancer report a steeper decline in mental health and social and sexual functioning using standardized $\mathrm{QoL}$ and depression measures compared with older women. ${ }^{52,53}$ Disruption of childrearing, employment outside the home, and early menopause/infertility are associated with psychological distress and may persist many years from diagnosis. ${ }^{54}$ The Cancer and Menopause Study (CAMS) evaluated the effects of breast cancer treatment on QoL and health. Although physical functioning was highest among the young women, social and emotional functioning were lowest among the youngest subset (ages 25-34 years) ${ }^{52}$ compared with population controls. Specific adjuvant treatments were not associated with lower QoL scores in this study, although the transition to menopause was associated with poorer emotional functioning. This finding suggests that supportive measures to help ease this transition in reproductive health may help improve QoL among young women with breast cancer.

In addition to QoL, future fertility is of paramount concern among most AYA women with breast cancer. Of 657 women surveyed regarding fertility issues, $57 \%$ recalled fertility concerns at diagnosis, among which $29 \%$ reported that fertility concerns affected future treatment decisions. ${ }^{55}$ Evidence suggests that women with breast cancer are not well 
informed of the consequences of adjuvant chemotherapy on future fertility, including the possibility of amenorrhea and early menopause.

Fertility preservation options to help avoid chemotherapy-induced infertility include cryopreservation of ovarian tissue, mature oocytes, and embryos. ${ }^{51}$ The most efficacious method of fertility preservation is embryo cryopreservation; however, this process requires a participating male partner. Oocyte cryopreservation offers flexibility in the timing of in vitro fertilization, allowing for completion of breast cancer treatment and/or identification of a partner. Based on observational studies, no increased risk of chromosomal or congenital abnormalities is seen with the use of cryopreserved oocytes compared with fresh oocyte sampling. ${ }^{56}$ This method is no longer viewed as experimental, and is therefore covered by insurance, because good evidence (level B) shows its success rate with an acceptable safety profile.

Finally, although the use of LHRH agonists has the goal of preserving ovarian function, current studies show mixed results. This method is attractive, however, because it does not involve invasive reproductive techniques. Del Mastro et $\mathrm{al}^{57}$ randomized women undergoing chemotherapy for breast cancer to undergo either temporary ovarian suppression with the LHRH agonist triptorelin or chemotherapy alone. Patients treated with triptorelin plus chemotherapy experienced lower rates of early menopause than those treated with chemotherapy alone $(8.9 \%$ vs $25.9 \%$; odds ratio, $0.28 ; P<.001)$. In a more recent study of young patients with breast cancer treated with neoadjuvant chemotherapy, treatment with triptorelin did not decrease the outcome of amenorrhea and was therefore stopped early for futility. ${ }^{58}$

Because decisions facing AYA patients with breast cancer are complex, the authors recommend that a detailed discussion regarding the risks of chemotherapy on future fertility and options for preservation occur before initiation of systemic therapy. Consultation with a fertility specialist as part of the multidisciplinary approach should occur when appropriate.

\section{Conclusions}

Breast cancer in the AYA population is a unique entity with a need for individualized multidisciplinary care requiring complex decision-making. In addition to the traditional team of medical, radiation, and sur- gical oncologists, optimal care of AYA patients with breast cancer might also include medical geneticists, psychologists and psychiatrists, fertility specialists, financial counselors, and individuals/programs with expertise in occupational rehabilitation. Treatment decisions must be tailored to a complex biology, while also balancing the potential for treatment-related, long-term sequelae, future fertility, and QoL. Over the years, the care of AYA patients with breast cancer has gained national attention, as evidenced by the multicenter study Young and Strong: Education and Supportive Care Intervention Study for Young Women With Breast Cancer (ClinicalTrials. gov identifier: NCT01647607), available to AYA patients with breast cancer throughout the United States. The medical community must continue to strive to better understand the biology of AYA breast cancer, develop clinical trials specific to this patient population, and identify interventions that improve on QoL, both during and after treatment, with the overall goal of improving outcomes for this unique patient population.

\section{References}

1. Closing the gap: research and cancer care imperatives for adolescents and young adults with cancer; report of the Adolescent and Young Adult Oncology Progress Review Group. Available at: http://planning.cancer.gov/library/AYAO_PRG_Report_2006_ FINAL.pdf. Accessed July 30, 2013.

2. National Cancer Institute. A Snapshot of Adolescent and Young Adult Cancers. Available at: http://www.cancer.gov/ researchandfunding/snapshots/adolescent-young-adult. Accessed July 30, 2013.

3. Bleyer A, Barr R, Hayes-Lattin B, et al. The distinctive biology of cancer in adolescents and young adults. Nat Rev Cancer 2008;8:288-298.

4. Gabriel CA, Domchek SM. Breast cancer in young women. Breast Cancer Res 2010;12:212.

5. Gnerlich JL, Deshpande AD, Jeffe DB, et al. Elevated breast cancer mortality in young women $(<40$ years) compared with older women is attributed to poorer survival in early stage disease. J Am Coll Surg 2009;208:341-347.

6. Coombs NJ, Cronin KA, Taylor RJ, et al. The impact of changes in hormone therapy on breast cancer incidence in the US population. Cancer Causes Control 2010;21:83-90.

7. Anders CK, Johnson R, Litton J, et al. Breast cancer before age 40 years. Semin Oncol 2009;36:237-249.

8. Go RS, Gundrum JD. Cancer in the adolescent and young adult (AYA) population in the United States: current statistics and projections [abstract]. J Clin Oncol 2011;29(Suppl):Abstract 6072.

9. Ferlay J, Shin H, Bray F, et al. GLOBOCAN 2008 v2.0, Cancer Incidence and Mortality Worldwide: IARC CancerBase No. 10. Lyon, France: International Agency for Research on Cancer; 2010. Available at: http://globocan.iarc.fr. Accessed July 30, 2013. 
10. Jemal A, Center MM, DeSantis C, Ward EM. Global patterns of cancer incidence and mortality rates and trends. Cancer Epidemiol Biomarkers Prev 2010;19:1893-1907.

11. Kamangar F, Dores GM, Anderson WF. Patterns of cancer incidence, mortality, and prevalence across five continents: defining priorities to reduce cancer disparities in different geographic regions of the world. J Clin Oncol 2006;24:2137-2150.

12. Adami HO, Malker B, Holmberg L, et al. The relation between survival and age at diagnosis in breast cancer. $\mathrm{N}$ Engl J Med 1986;315:559.

13. Holli K, Isola J. Effect of age on the survival of breast cancer patients. Eur J Cancer 1997;33:425-428.

14. El Saghir NS, Seoud M, Khalil MK, et al. Effects of young age at presentation on survival in breast cancer. BMC Cancer 2006;6:194.

15. Nixon AJ, Neuberg D, Hayes DF, et al. Relationship of patient age to pathologic features of the tumor and prognosis for patients with stage I or II breast cancer. J Clin Oncol 1994;12:888-894.

16. Kollias J, Elston C, Ellis I, et al. Early-onset breast cancerhistopathological and prognostic considerations. Br J Cancer 1997;75:1318-1323.

17. Johnson RH, Chien FL, Bleyer A. Incidence of breast cancer with distant involvement among women in the United States, 1976 to 2009. JAMA 2013;309:800-805.

18. Colleoni M, Rotmensz N, Robertson C, et al. Very young women (<35 years) with operable breast cancer: features of disease at presentation. Ann Oncol 2002;13:273-279.

19. Anders CK, Hsu DS, Broadwater G, et al. Young age at diagnosis correlates with worse prognosis and defines a subset of breast cancers with shared patterns of gene expression. J Clin Oncol 2008;26:3324-3330.

20. Azim HA Jr, Michiels S, Bedard PL, et al. Elucidating prognosis and biology of breast cancer arising in young women using gene expression profiling. Clin Cancer Res 2012;18:1341-1351.

21. Perou CM, Sørlie T, Eisen MB, et al. Molecular portraits of human breast tumours. Nature 2000;406:747-752.

22. Sørlie T, Tibshirani R, Parker J, et al. Repeated observation of breast tumor subtypes in independent gene expression data sets. Proc Natl Acad Sci U S A 2003;100:8418-8423.

23. The Cancer Genome Atlas Network. The Cancer Genome Atlas Network. Comprehensive molecular portraits of human breast tumours. Nature 2012;490:61-70.

24. Anders CK, Fan C, Parker JS, et al. Breast carcinomas arising at a young age: unique biology or a surrogate for aggressive intrinsic subtypes? J Clin Oncol 2011;29:e18-20.

25. Parker JS, Mullins M, Cheang MC, et al. Supervised risk predictor of breast cancer based on intrinsic subtypes. J Clin Oncol 2009;27:1160-1167.

26. Lim E, Vaillant F, Wu D, et al. Aberrant luminal progenitors as the candidate target population for basal tumor development in BRCA1 mutation carriers. Nat Med 2009;15:907-913.

27. Goodwin PJ. Management of familial breast cancer risk. Breast Cancer Res Treat 2000;62:19-33.

28. Brose MS, Rebbeck TR, Calzone KA, et al. Cancer risk estimates for BRCA1 mutation carriers identified in a risk evaluation program. J Natl Cancer Inst 2002;94:1365-1372.

29. Malone KE, Daling JR, Neal C, et al. Frequency of BRCA1/ BRCA2 mutations in a population-based sample of young breast carcinoma cases. Cancer 2000;88:1393-1402.

30. Atchley DP, Albarracin CT, Lopez A, et al. Clinical and pathologic characteristics of patients with BRCA-positive and BRCA- negative breast cancer. J Clin Oncol 2008;26:4282-4288.

31. Gonzalez-Angulo AM, Timms KM, Liu S, et al. Incidence and outcome of BRCA mutations in unselected patients with triple receptor-negative breast cancer. Clin Cancer Res 2011;17:10821089.

32. Bane AL, Beck JC, Bleiweiss I, et al. BRCA2 mutation-associated breast cancers exhibit a distinguishing phenotype based on morphology and molecular profiles from tissue microarrays. Am J Surg Pathol 2007;31:121-128.

33. Carey LA. American Society of Clinical Oncology: Self-Evaluation Program: Breast Cancer. ASCO Self Evaluation Program (ASCOSEP): Alexandria, VA: American Society of Clinical Oncology; 2010:113.

34. Kleihues $P$, Schäuble $B$, Zur Hausen $A$, et al. Tumors associated with $\mathrm{p} 53$ germline mutations: a synopsis of 91 families. Am J Pathol 1997;150:1-13.

35. Masciari S, Dillon DA, Rath M, et al. Breast cancer phenotype in women with TP53 germline mutations: a Li-Fraumeni syndrome consortium effort. Breast Cancer Res Treat 2012;133:1125-1130.

36. Melhem-Bertrandt A, Bojadzieva J, Ready KJ, et al. Early onset HER2-positive breast cancer is associated with germline TP53 mutations. Cancer 2012;118:908-913.

37. Wilson JRF, Bateman AC, Hanson H, et al. A novel HER2-positive breast cancer phenotype arising from germline TP53 mutations. J Med Genet 2010;47:771-774.

38. Langerod A, Zhao H, Borgan O, et al. TP53 mutation status and gene expression profiles are powerful prognostic markers of breast cancer. Breast Cancer Res 2007;9:R30.

39. Eng C. PTEN Hamartoma Tumor Syndrome (PHTS). Available at: http://www.ncbi.nlm.nih.gov/books/NBK1488/. Accessed July 30, 2013.

40. Daly MB, Axilbund JE, Buys SS, et al. NCCN Clinical Practice Guidelines in Oncology for Genetic/Familial High-Risk Assessment: Breast and Ovarian. Version 3, 2013. Available at: NCCN.org. Accessed July 30, 2013.

41. Tai YC, Domchek S, Parmigiani G, Chen S. Breast cancer risk among male BRCA1 and BRCA2 mutation carriers. J Natl Cancer Inst 2007;99:1811-1814

42. Swerdlow AJ, Schoemaker MJ, Higgins CD, et al. Cancer incidence and mortality in men with Klinefelter syndrome: a cohort study. J Natl Cancer Inst 2005;97:1204-1210.

43. Theriault RL, Carlson RW, Allred C, et al. NCCN Clinical Practice Guidelines in Oncology for Breast Cancer. Version 3 2013. Available at: NCCN.org. Accessed July 30, 2013.

44. Ovarian ablation in early breast cancer: overview of the randomised trials. Early Breast Cancer Trialists' Collaborative Group. Lancet 1996;348:1189-1196.

45. Gnant M, Mlineritsch B, Schippinger W, et al. Endocrine therapy plus zoledronic acid in premenopausal breast cancer. N Engl J Med 2009;360:679-691.

46. Roché H, Kerbrat P, Bonneterre J, et al. Complete hormonal blockade versus epirubicin-based chemotherapy in premenopausal, one to three node-positive, and hormone-receptor positive, early breast cancer patients: 7-year follow-up results of French Adjuvant Study Group 06 randomised trial. Ann Oncol 2006;17:1221-1227.

47. Klijn J, Blamey R, Boccardo F, et al. Combined tamoxifen and luteinizing hormone-releasing hormone (LHRH) agonist versus LHRH agonist alone in premenopausal advanced breast cancer: a meta-analysis of four randomized trials. J Clin Oncol 2001;19:343353. 
Breast Cancer in Young Women

48. Cuzick J, Ambroisine L, Davidson N, et al. Use of luteinisinghormone-releasing hormone agonists as adjuvant treatment in premenopausal patients with hormone-receptor-positive breast cancer: a meta-analysis of individual patient data from randomised adjuvant trials. Lancet 2007;369:1711-1723.

49. Carlson RW, Theriault R, Schurman CM, et al. Phase II trial of anastrozole plus goserelin in the treatment of hormone receptorpositive, metastatic carcinoma of the breast in premenopausal women. J Clin Oncol 2010;28:3917-3921.

50. Loible S, Jackisch C, Gade S, et al. Neoadjuvant chemotherapy in the very young 35 years of age or younger. Cancer Res 2012;72(Suppl 24):33s.

51. Lee SJ, Schover LR, Partridge AH, et al. American Society of Clinical Oncology recommendations on fertility preservation in cancer patients. J Clin Oncol 2006;24:2917-2931.

52. Ganz PA, Guadagnoli E, Landrum MB, et al. Breast cancer in older women: quality of life and psychosocial adjustment in the 15 months after diagnosis. J Clin Oncol 2003;21:4027-4033.

53. Bines J, Oleske DM, Cobleigh MA. Ovarian function in premenopausal women treated with adjuvant chemotherapy for breast cancer. J Clin Oncol 1996;14:1718-1729.

54. Ganz PA, Desmond KA, Leedham B, et al. Quality of life in longterm, disease-free survivors of breast cancer: a follow-up study. J Natl Cancer Inst 2002;94:39-49.

55. Partridge AH, Gelber S, Peppercorn J, et al. Web-based survey of fertility issues in young women with breast cancer. J Clin Oncol 2004:22:4174-4183.

56. The Practice Committees of the American Society for Reproductive Medicine and the Society for Assisted Reproductive Technology. Mature oocyte preservation: a guideline. Fertil Steril 2013;99:37-43.

57. Del Mastro L, Boni L, Michelotti A, et al. Effect of the gonadotropinreleasing hormone analogue triptorelin on the occurrence of chemotherapy-induced early menopause in premenopausal women with breast cancer. JAMA 2011;306:269-276.

58. Munster PN, Moore AP, Ismail-Khan R, et al. Randomized trial using gonadotropin-releasing hormone agonist triptorelin for the preservation of ovarian function during (neo) adjuvant chemotherapy for breast cancer. J Clin Oncol 2012;30:533-538. 